\title{
El derecho al gemido. Notas para pensar la ESI desde una posición prosexo
}

\section{val flores"}

Me propongo trazar algunos pensamientos en relación a la Educación Sexual Integral (ESI) desde una lectura aberrante, un pensamiento dis/torsionado por preguntas intolerables, esas que suelen quedar acalladas en el régimen de inteligibilidad de la normalidad educativa, las que provocan un radical extrañamiento en los constructos y los órdenes conceptuales de las sexualidades y en nuestros imaginarios pedagógicos y eróticos, las que no son populares porque se inmiscuyen en los propios procesos de producción del conocimiento y nuestros límites pedagógicos y políticos. Me planteo pensar la ESI como una arriesgada aventura intelectual feminista y cuir desde una posición prosexo, como marco para problematizar la fuerza heterosexualizante de la cultura escolar, y los supuestos antisexo que abonan las retóricas del peligro, la prevención y el riesgo, como articuladores de las prácticas en relación a ESI y que provocan que ciertos placeres y prácticas sexuales sean construidos como ininteligibles, convertidos en impensables e indeseables para el contexto escolar.

$* * *$

La ESI como política pública establece derechos y obligaciones en lxs actores del sistema educativo a partir de la Ley Nacional 26150 de Educación Sexual Integral, que la inscribe como un asunto de derechos humanos. En las prácticas escolares y dinámicas institucionales, la educación sexual es un campo de tensión crítica, un territorio de disputas de saberes, de modos de subjetivación, de paradigmas de inteligibilidad del género, de valores sociales y culturales, en definitiva, una disputa por la legitimidad de ciertos cuerpos, ciertas prácticas, ciertos deseos. Entonces, más que pensar la ESI como un programa uniforme que designa un modelo didáctico-curricular a aplicar, supuestamente dotado de una homogeneidad de formas y contenidos, el desafío es imaginar la ESI como una diáspora de experiencias situadas y singulares que interrelacionan (o no) los procesos de generización y sexualización de los cuerpos de estudiantes y docentes con las circunstancias geo-socio-políticas locales, de manera que muestra cómo los regímenes hegemónicos de lo sensible que promueven las instituciones escolares instituyen la decibilidad, visibilidad y legibilidad de los cuerpos y placeres.

Antes que sustancializar la ESI como legalidad subjetivante, es preciso reconocerla como un campo de problemas y de interrogaciones pedagógicas y políticas sobre los modos normalizados del pensar y del enseñar (heterosexualizados, generizados, racializados, capacitistas, adultocéntricos). Para ello, hay que situar la ESI en una trama de leyes en defensa de la no discriminación y el reconocimiento de la diversidad sexual, ${ }^{1}$ sancionadas de forma continua desde fines de la década de 1990 . El conjunto de estas leyes se asienta sobre una concepción liberal del sujeto de derechos. El sujeto
* Maestra, escritora, activista de la disidencia sexual lesbiana, feminista, prosexo. Se dedica a la escritura ensayística/poética y a la realización de talleres y performances como modos de intervención estéticamodos de intervención estética-
política-pedagógica. Algunas de sus publicaciones son: Interruqciones. Ensayos de poética activista (2013), La intimidad del procedimiento. Escritura lesbiana sur como prácticas de sí (2016), $F(r)$ icciones pedagógicas. Escrituras, sexualidades y educación (comp. con Agustina Peláez, 2017) y Tropismos de la disidencia (2017).
(comp. con Agustina Peláz, 2017)
1. Entre ellas, la Ley de Matrimonio Civil entre parejas del mismo sexo (26618), la Ley de Identidad de Género (26743), la Ley de Prevención y sanción de la trata de personas y asistencia a sus víctimas (26364), la Ley de Protec ción integral para prevenir, sancionar y erradicar la violencia contra las mujeres (26485), la Ley de Acceso integral a los procedimientos y técnicas médico-asistenciales a los y técnicas médicamente asistida (26862). 
2. Bondage, dominación, sumisión, sadomasoquismo. de derechos sexuales que presupone es un sujeto configurado dentro de la tradición del liberalismo político, lo que impone límites a la ciudadanía y abona ciertas normas mediante las cuales se le da sentido a la sexualidad, construyendo al mismo tiempo unxs "otrxs" sexuales bajo los requisitos de la respetabilidad y normalización (Sabsay, 2012: 142). Una de las implicaciones que tiene la judicialización de la libertad y la justicia sexuales, sobre todo cuando estas son entendidas casi exclusivamente en términos de derechos individuales (Sabsay, 2014: 55), consiste en que la sexualidad es asumida como una realidad ontológica, como un hecho inalienable y no el efecto de una episteme particular, de forma que naturaliza que esa epistemología sexual capaz de definir quiénes somos se refiere solo a formas muy específicas de entender nuestra concepción de los cuerpos y la vida corporal. Intervenir en el campo de la ESI como una activista lesbiana y maestra prosexo implica sostener una interrogación incesante de las políticas sexuales y las posturas antisexo en las leyes, normas institucionales y relaciones personales, en tanto práctica ética que disputa los sentidos que se ciernen sobre lo sexual y que crean exclusiones, segregaciones, jerarquías, desigualdades.

Así, la ESI se presenta como una economía pedagógica de los saberes, los cuerpos, los placeres y la imaginación que es urgente interpelar y contrastar con otros modos de producción de saberes no escolarizados vinculados a esxs "otrxs" que fueron lanzadxs a los márgenes de la ciudadanía sexual, como lxs trabajadorxs sexuales, practicantes de BDSM, ${ }^{2}$ productorxs y consumidorxs de pornografía y posporno, alianzas poliamorosas o pactos no monogámicos, etcétera. De este modo, la ESI puede ser pensada como un archivo público -no solo estatal-y potencial de prácticas educativas creativas, escrituras contagiosas, afectos descolonizadores, imaginaciones indisciplinadas, modos críticos de subjetivación, memorias del daño, de los genocidios y del éxtasis celebratorio de la sobrevivencia.

$* * *$

Un pensamiento pedagógico-político articulado por una perspectiva feminista cuir no consiste en definir identidades ni representarlas como un objetivo en sí mismo, sino que es un llamado a resistir las prácticas normales y las prácticas de normalización sexo-genérica, racial, corporal, nacional, etcétera (flores, 2013: 216). Consiste en un modo de hacer crítico que desestabiliza nuestras propias categorías del pensamiento pedagógico al postular la producción de la normalización como un problema de la cultura y del pensamiento, que cuestiona las categorías que definen el campo en el que las identidades hacen sentido (Sabsay, 2014).

De esta manera, sospecha y destruye las esperanzas espoleadas por el individualismo liberal asociadas con la inclusión representacional de las identidades LGTTTBI en los currículos como una estrategia de subversión contra la heteronormatividad, ya que la pedagogía antinormativa/cuir, más que una nueva forma de conocimiento, implica la capacidad de plantear preguntas sobre los recorridos para llegar a saber y construir sentido. Como sugiere Britzman, se ocupa en primer lugar de una práctica radical de deconstrucción de la normalidad, entonces, en lugar de presentar al conocimiento (correcto) como respuesta o solución, el conocimiento se constituye como una pregunta interminable (Luhmann, 1998).

Uno de los intereses de esta pedagogía es el estudio sobre los límites como un problema de pensabilidad, ese punto en el que el pensamiento se detiene, ante lo cual Britzman se pregunta, "¿qué hace que algo sea pensable?" (Britzman, 2016). Abordar el límite del pensamiento -dónde se detiene, lo que no puede soportar conocer, lo que debe cancelar para pensar como lo hace- permite considerar las condiciones culturales que operan para desestimar como irrelevante o valorizar como relevante 
un tipo particular de pensamiento pedagógico. En este caso, me interesa reflexionar sobre los agenciamientos de placer como política sexual que suelen quedar ausentes en los discursos sobre ESI, más preocupados y enfocados a la prevención, el peligro, el riesgo, donde pareciera que no hay sexualidades a ser exploradas y pensadas, donde no hay preguntas, sino respuestas prefabricadas, aun en las propuestas más críticas. Estas reflexiones son una invitación a pensar ¿qué sexo admite la ESI?, ¿qué prácticas sexuales hace inteligibles y cuáles quedan en la opacidad de lo indeseable, en el ostracismo de la perversión, en el campo de la abyección?, ¿cuál es el sueño sexual de la ESI?

Es imposible pensar la ESI fuera de una coyuntura histórica específica. Estamos viviendo en un contexto sociopolítico de represión estatal, militarización del espacio público, castigo a la protesta social, criminalización de lesbianas y trans, de aumento sistemático de agresiones hacia la población LGTTTB, persecución a los pueblos originarios, de negacionismo, ajuste y despidos masivos, de avance de los promotorxs de "la ideología de género", el desmantelamiento de los programas sociales del estado, todas tecnologías de disciplina social y sexual. Desde los feminismos asistimos a su efervescencia y auge popular, sin embargo predominan las retóricas y visualidades de victimización que propagan la maquinaria mediática, el estado y los feminismos de corte más punitivista y abolicionista que han ocupado la representación del movimiento, en las que prevalecen de manera casi exclusiva y excluyente los tópicos del femicidio, la violencia, la trata, el abuso, el acoso y el aborto. Sin menoscabo de la importancia vital de la visibilización y denuncia de las violencias heteropatriarcales y capitalistas estructurales, cabe comprender los modos en que funciona el pánico sexual como forma de control de nuestras sexualidades y cómo los discursos educativos desde la ESI funcionan en este sentido. Tal como advertía Gayle Rubin, en épocas de crisis emerge una preocupación por la peligrosidad desquiciada en relación a lo sexual, son periodos históricos en los que la sexualidad es más intensamente controlada y más abiertamente politizada (Rubin, 1989).

Los pánicos sexuales producen efectos concretos, la mayoría de las veces prejuicios y discriminaciones que se graban a fuego en la memoria colectiva, que instalan definiciones normativas acerca de las sexualidades, además de legislaciones represivas, que disponen las eróticas permisibles y deseables. De esta manera, se crea un clima político emocional tal que es imposible hablar de sexo por fuera del paradigma del sexo como peligro (Daich, 2013). ${ }^{3}$ No podemos negar que las escuelas están atravesadas hoy por el pánico sexual, lo que aparece recurrentemente en los relatos de maestrxs y profesorxs que expresan el temor de tocar a sus estudiantes y de tocar ciertos temas que serían sensibles a la moral de la comunidad educativa.

No se trata solo de combatir las políticas antisexo que propagan los sectores conservadores y religiosos que se oponen a la implementación de la ESI, sino de analizar esos silencios y supresiones en relación al sexo que articulan las propias pedagogías de la ESI, los significantes que hegemonizan sus contenidos como discursos de derechos, cuando los ideales de la ciudadanía sexual bajo el modelo del individualismo liberal se basan en la clasificación de un espectro limitado de identidades discretas y normalizadas (Sabsay, 2012: 150). Se trata de preguntarnos por los límites de lo inteligiblemente pedagógico, así como de lo sexualmente (im)posible de ser enseñado en las aulas.

$* * *$

Prosexo es una posición política crítica ${ }^{4}$ que integra las genealogías críticas de los feminismos, el activismo cuir y de la disidencia sexual, y busca promover la creatividad sexual y erótica, manteniendo un horizonte abierto de posibilidades y deseabilidades
3. Al respecto, Daich señala uno de los pánicos que ha atravesado en este último tiempo el debate social y feminista, referido a la trata con fines de explotación sexual y el trabajo sexual. "Todo lo que se concte "Todo lo que se conecte con el merca' del sexo es pasible de ser leído en clave de 'esclavitud' y pura violencia, pura explotación, y ha comenzado así una cruzada moral salvacionista que no complejiza, no explica ni describe los fenómenos, sino que los valoran y los juzgan. Así, lo que hoy está en el ojo de la tormenta es el sexo comercial y las mismas definiciones de sexualidad" (2013). A su vez, una performance posporno realizada en el marco de un debate sobre trabajo sexual realizado en la Universidad Nacional de Villa María (Córdoba), volvió a ser objeto de pánico sexual poxual por parte de las autoridades universitarias. Para un análisis del temor que produce el sexo en el ámbito universitario, ver "El posporno va a la universidad" de Noe Gall, en https:// www.elcohetealaluna.com/el-posporno-va-a-la-universidad-publica/

4. Para más referencias a nivel local, ver Noe Gall (2013) "Pro sexo", en Página 12, viernes 13 de septiembre, Buenos Aires, http://www.pagina12. com.ar/diario/suplementos/las12/ subnotas/8303-842-2013-09-13.htm 
5. A partir de una relectura de Butler, Canseco nos ofrece el concepto de eroticidad como articulación política del placer sexual, al tener en cuenta los marcos culturales de inteligibilidad sexual y de género con sus respectivas normas que regulan preguntarnos por las normas que regulan la deseabilidad pública de los cuerpos, preguntarnos por qué podemos aprehender ciertos cuerpos como eróticos y no otros y qué condiciones sociales habilitan que esa aprehensión tenga o no tenga lugar" (Canseco, 2017: 197). que amplíe y multiplique los imaginarios disponibles y los repertorios de sus prácticas eróticas desde una concepción benigna del sexo y de su variabilidad inaudita, oponiéndose a la falsa ecuación de que el sexo siempre es equivalente a violencia, una concepción que atemoriza y des-empodera. Comprende las guerras capilares del sexo como formas de mantenimiento y ejercicio de un régimen de privilegios heterosexuales, racistas, patriarcales, capitalistas, cisexuales, nacionalistas, que distribuye la vulnerabilidad económica, política, erótica y cultural de manera mortíferamente desigual. Mantiene una sospecha activa sobre los modos de represión y vigilancia en los espacios públicos e íntimos acerca de los cuerpos, las sexualidades y los deseos, que atenta contra la higienización moral de lo público y la profilaxis de la disidencia sexual.

En los debates feministas locales, una posición prosexo suele quedar restringida al reconocimiento del trabajo sexual, no obstante, su espectro de actuación es más vasto. Casi como residuo pedagógico de un modo de conocer, eso que se destierra a los márgenes pero que está con frecuencia justo en el centro del pensamiento mismo (Ahmed, 2015:25), una posición prosexo se ve interpelada por la lengua antisexo en la producción de sentidos sobre la ESI y las violencias epistemológicas que supone. Con lengua antisexo no me refiero a las condenas clericales, sino a cómo el saber público sobre las sexualidades, los deseos y las identidades que se origina en las instituciones escolares y programas curriculares produce un cierto tipo de sexo legítimo y aceptable.

Como parte de los horizontes emancipadores de una posición prosexo se encuentra la justicia erótica, regida por los principios del placer, la satisfacción y el deleite sexual, el consentimiento entre quienes realizan las prácticas sexuales y un clima público que impide la violencia, el estigma y la discriminación. En este sentido, Beto Canseco, 5 teórico y activista prosexo de Córdoba, nos propone pensar el concepto de justicia erótica como articulador de dos derechos habitualmente considerados como derechos escindidos en los discursos sociales y también en ciertas corrientes feministas: el derecho al placer sexual y el derecho a la protección contra la violencia sexual. Así, el derecho al placer sexual como necesidad y urgencia ética de producir condiciones sociales de manera igualitaria para que los cuerpos puedan verse involucrados en experiencias sexuales, está íntimamente vinculado al derecho que garantiza una minimización de la exposición al daño.

En el campo de la pedagogía y de la educación sexual, la eroticidad nos mueve a interpelarnos por las deseabilidades que construye el conocimiento escolar institucionalizado en relación a los cuerpos, las identidades, las prácticas sexuales y los afectos, nos convoca a abrir incómodos y espinosos interrogantes sobre los marcos normativos de ese saber y sus efectos performativos sobre la producción corporal, en especial sobre los cuerpos de la infancia.

Podemos pensar que las preguntas por la deseabilidad en términos de deseo sexual y de pulsión intelectual y erótica son también preguntas acerca de la ignorancia como forma de saber y de practicar un modo heterosexualizante del conocer. En este sentido, retomo y reformulo una de las preguntas que Britzman se hacía en uno de sus textos: “¿Por qué los educadores continúan tan dispuestos a argumentar a favor y en contra del sexo, a vincular el constructo del sexo apropiado con el constructo de la edad apropiada y a preocuparse sobre cuál conocimiento existe en cuáles cuerpos en cuáles circunstancias?" (Britzman, 2001). El sentido de lo apropiado ha sido central en debates y propuestas sobre ESI, es un criterio que surge aun en las perspectivas más críticas y nos invita a cuestionarnos acerca de cómo el modo apropiado de pensar las sexualidades y cuerpos en la escuela se constituye en una precondición para ser reconocido como un pensamiento válido y un sentimiento legítimo. En general, ese modo apropiado de abordar la ESI suele estar direccionado bajo los preceptos de prevenir el embarazo, erradicar la violencia, prevenir el abuso, fomentar la sexualidad 
"responsable", preservar de las infecciones de transmisión sexual, prevenir la trata/ prostitución, entre otros.

$* * *$

Si los afectos son políticas de conocimiento, habría que examinar en nuestros venturosos proyectos feministas sobre ESI los pánicos y ansiedades que se (nos) juegan en una economía de lo visible, lo pensable y lo enseñable sobre el sexo y las sexualidades en el espacio educativo, sobre todo en las formas del coger como prácticas performativas que componen las identidades sexuales y de género. Por eso, tal vez uno de los desafíos de la ESI sea tener en cuenta y lidiar con la inestabilidad e inaprensibilidad del lenguaje del sexo, activar modos de desaprendizaje de las formas normalizadas del imaginar el sexo y el desear y de pedagogías que no terminen por desexualizar el lenguaje del sexo como modo apropiado y aceptado de hablar las sexualidades.

Estas interpelaciones prosexo y anticensura no buscan desestimar la ESI como artefacto crítico para una política sexual feminista, sino incidir en el montaje colectivo de una urgente imaginación pedagógica que haga del "derecho al gemido" (Navarrete, 2014) una demanda prioritaria para la infancia y también para lxs educadorxs, cuyos gemidos se ven privatizados bajo el imperativo moral que domina el sistema educativo. ${ }^{6}$ A contrapelo de un llamado a la inclusión curricular y la traducción estatal de prácticas sexuales marginalizadas, estas notas son una incitación a la crítica radical de los placeres y sus supresiones epistemológicas que procure expandir el lenguaje pedagógico como actividad erótica y disponer espacios para explorar la libertad erótica, las propias fantasías y deseos, la negociación del poder y que tensione la ESI como una forma de curiosidad epistémica y de justicia erótica y pedagógica.

6. Resultan muy fructíferos los diálogos en espacios de formación docente cuando lxs educadorxs nos reconocemos como consumidorxs de porno, productorxs de posporno y de prácticas sexuales que desgenitalizan la sexualidad, abriendo un campo de posibilidades para desorganizar los modelos políticos de comprensión funcionalista y positivista que dominan el saber escolar sobre el cuerpo. Al mismo tiempo, insisto en que la respetabilidad académica y la asepsi sexual como requisito del régime de producción de conocimientos
también precisa ser interrogado como parte de la lucha por la justicia erótica. ¿Desde la disidencia sexual queremos seguir produciendo académicxs impolutxs, desexualizadxs e incontaminadxs por los placeres de la carne?" (flores, 2018). 


\section{Dibliografía}

»Ahmed, S (2015). La política cultural de las emociones. Programa Universitario de Estudios de Género. Universidad Nacional Autónoma de México.

" Britzman, D. (2001). “Curiosidad, sexualidad y currículum”. En G. Lopez Louro (comp.), O corpo educado. Pedagogias da sexualidade. Belo Horizonte, Brasil: Autêntica.

” Britzman, D. (2016). “¿Hay una pedagogía queer? O, no leas tan recto”. Revista de Educación, 9, 13-34.

"Canseco, A. (2017). Eroticidades precarias. La ontología corporal de Judith Butler. Córdoba, Argentina: Asentamiento Fernseh.

"Daich, D. (2013). “De pánicos sexuales y sus legados represivos”. Zona Franca. Revista del Centro de Estudios Interdisciplinario sobre Mujeres, 22, 31-40.

" flores, v. (2013) interruqciones. Ensayos de poética activista. Escritura, política, pedagogía. Neuquén: La Mondonga dark.

»flores, v. (2015) “Decir prosexo". En S. Song, C. B. Daring, S. Grohmann y v. flores, Cuirizar el anarquismo. Ensayos sobre género, poder y deseo. Córdoba, Argentina: Bocavulvaria.

» flores, v. (2017) “Diásporas de la ESI”. 6 Jornadas ESI “Cuerpos, educación y sociedad”. Instituto Superior de Formación Docente № 809. Esquel, Argentina.

" flores, v. (2018) “Por un feminismo pervertido". En G. Rubin En el crepúsculo del brillo. La teoría como justicia erótica. Córdoba, Argentina: Bocavulvaria.

»Luhmann, S. (1998). “¿Cuirizar/Cuestionar la pedagogía? o, La pedagogía es una cosa bastante cuir". En W. F. Pinar (Ed.), Queer Theory in Education. Mahwah, Estados Unidos: Lawrence Erlbaum Associates, Inc.

» Navarrete, L. (2014). “Atentar contra la infancia”. En IV Circuito de Disidencia Sexual. Tráficos Feministas. Colectivo Utópico de Disidencia Sexual (CUDS). Santiago de Chile, Chile.

»Rubin, G. (1989). "Reflexionando sobre el sexo: notas para una teoría radical de la sexualidad”. En Carole V., Placer y peligro: explorando la sexualidad femenina. Madrid, España: Revolución.

»Sabsay, L. (2012). “Algunas paradojas de la ciudadanía sexual”. Debates y Combates, 3, 137-162.

»Sabsay, L. (2014). "Políticas queer, ciudadanías sexuales y decolonización“. En D. Falconí y S. Castellanos, M. A. Viteri (eds.), Resentir lo queer en América Latina. Diálogos con/desde el Sur (pp. 45-58). Barcelona, España: Egales.

» Taormino, T., Parreñas Shimizu, C., Penley, C., Miller-Young, M. (Eds.) (2016) Porno Feminista. Las políticas de producir placer (Traducción Martínez B.). Santa Cruz de Tenerife, España: Melusina. 